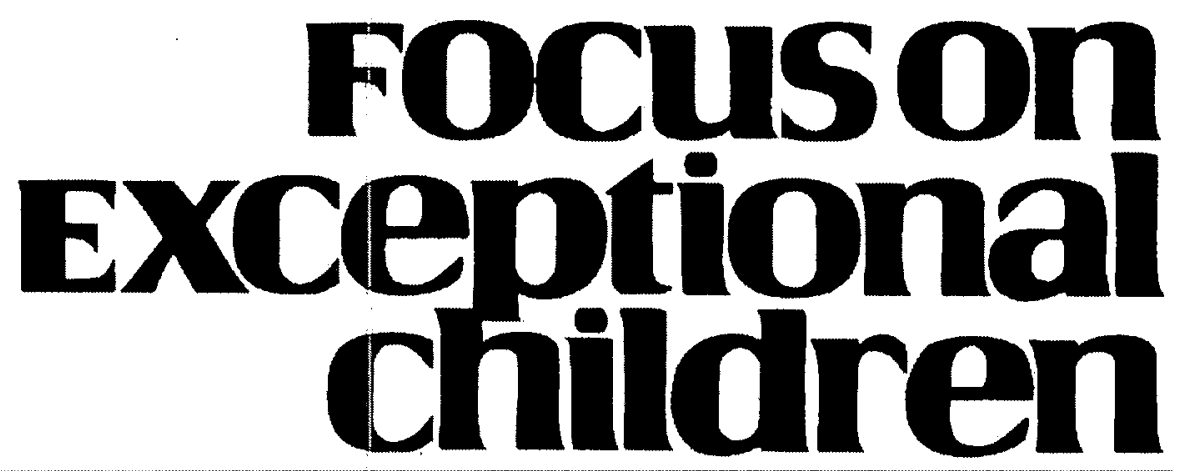

\title{
Academic Instruction for Students with Severe Disabilities
}

\author{
Victoria Knight, Diane Browder, Barbara Agnello, and Angela Lee
}

Most students who attend America's schools have the opportunity to become literate in reading, mathematics, science, and other content areas. Only recently have educators realized that this same educational opportunity should be available to students with moderate and severe developmental disabilities. Soon after students with severe disabilities received the right to a free public education, special educators proposed planning curricula based on a criterion of ultimate functioning in the community (Brown, Nietupski, \& Hamre-Nietupski, 1976). In applying a criterion of community functioning, educators sometimes assumed students with severe disabilities should learn skills of daily living instead of academic content, rather than as a supplement to this learning. Independent functioning in the community is important for all students, but this includes acquiring some degree of academic competence.

Changes in federal policy and new research have promoted a new emphasis on teaching academic content. Under the Individuals with Disabilities Education Act (IDEA, 1997, 2004), students with disabilities must (a) have access to the general curriculum, (b) be involved in the general curriculum, and (c) progress in the general curriculum (IDEA, 2004). Students who are unable to participate in the large-scale general assessments in content areas like reading, mathematics, and science must have the opportunity to show learning through an alternate assessment.

Recent research has provided evidence that when given the opportunity to learn some defined academic content, students with moderate and severe developmental disabilities can do so. For example, Jameson, McDonnell, Johnson, Riesen, and Polychronis (2007) demonstrated that students acquired vocabulary aligned with grade-appropriate content in areas such as science and social studies when systematic instruction was embedded in general education classes. Jimenez, Browder, and Courtade (2008) found that students with moderate intellectual disabilities learned to perform a simple algebraic equation. Dymond et al. (2006) increased the participation of students with severe disabilities in a high school science class using principles of universal design of learning (UDL; CAST, 2008). Studies such as these demonstrate that students with severe disabilities can rise to higher expectations for learning academic content.

\footnotetext{
Victoria Knight is a research assistant for Project MASTERY, Diane Browder is the Snyder Distinguished Professor of Special Education, Barbara Agnello is the clinical director for developmental disabilities, and Angela Lee is a research assistant for RAISE at the University of North Carolina at Charlotte.
} 
Teaching academics to students with severe disabilities just because they can learn the content is not the primary reason for doing so. Browder, Wakeman et al. (2007) described reasons to teach academic content to students with severe disabilities. First and foremost, these educational opportunities increase competence for adult living. Through English/Language Arts (ELA) instruction, students gain a means for accessing and understanding the various forms of text encountered in daily life. Activities may include locating information in a newspaper, reading a story for pleasure, or conducting an internet search. Through mathematics, students gain skills that are useable in wide variety of activities such as cooking a meal, negotiating a map, or planning a party. More complex skills like plotting points on a plane enhance career opportunities (e.g., machinists use coordinate planes). Similarly, experiences with science can lead to lifelong hobbies or careers. A second reason to teach academics proposed by Browder, Wakeman et al. (2007) is that expectations for students with severe disabilities have increased in the past two decades. Students can learn and do

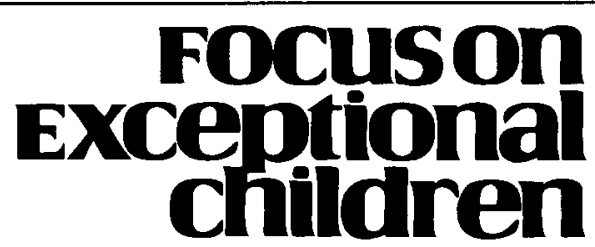

ISSN 0015-511X FOCUS ON EXCEPTIONAL CHILDREN (USPS 203-360) is published monthly except June, July, and August as a service to teachers, special educators, curriculum specialists, administrators, and those concerned with the special education of exceptional children. This publication is annotated and indexed by the ERIC Clearinghouse on Handicapped and Gifted Children for. publication in the monthly Current Index to Journals in Education (CIJE) and the quarterly index, Exceptional Children Education Resources (ECER). The full text of Focus on Exceptional Children is also available in the electronic versions of the Education Index. It is also available in microfilm from Serials Acquisitions, National Archive Publishing Company, P.O. Box 998, Ann Arbor, MI 48106-0998. Subscription rates: individual, $\$ 48$ per year; institutions, $\$ 66$ per year. Copyright $\odot$ 2010, Love Publishing Company. All rights reserved. Reproduction in whole or part without written permission is prohibited. Printed in the United States of America. Periodical postage is paid at Denver, Colorado. POSTMASTER: Send address changes to:

$$
\begin{gathered}
\text { Love Publishing Company } \\
\text { Executive and Editorial Office } \\
\text { P.O. Box } 22353 \\
\text { Denver, Colorado } 80222 \\
\text { Telephone (303) 221-7333 }
\end{gathered}
$$

\section{CONSULTING EDITORS}

Steve Graham Vanderbilt University
Ron Nelson University of Nebraska-Lincoln

Eva Horn

University of Kansas

Carrie E. Watterson

Senior Editor
Stanley F. Love

Publisher much more than once believed. With this increased learning, students have increased opportunities. Providing academic content instruction also promotes educational equality. Students who are nondisabled do not have to master skills like making their beds before learning skills like how to read. Similarly, students with severe disabilities should not be held to a double standard of learning all life skills before learning academic content. Finally, acquiring academic competence can increase opportunities for self-determination through having more tools to gain information and demonstrate ability.

Given these reasons for promoting academic content learning for students with severe disabilities, the need exists for evidence-based practices to enhance student academic achievement. Recent comprehensive reviews on academic content reveal two important facts for planning: that students can learn academic skills and that the past curricular focus has been extremely limited. In cross-referencing research on reading with the National Reading Panel's (NRP; 2000) recommendations in reading, Browder, Wakeman, Spooner, Ahlgrim-Delzell and Algozzine (2006) found almost all studies focused on sight word learning, and only a few of these included measures of comprehension. Almost none focused on the critical skills of phonics or phonemic awareness. In comparing research in mathematics to the strands of content proposed by the National Council of Teachers of Mathematics (NCTM), Browder, Spooner, Ahlgrim-Delzell, Harris, and Wakeman (2008) found that most studies targeted numbers and operations or measurement; few considered algebra, geometry, or data analysis. Courtade, Spooner, and Browder (2007) found virtually no studies in science until they searched the daily living skills literature and found 11 studies that taught some science concepts. At first, these outcomes may seem discouraging for finding guidance to teach academic content to students with severe disabilities. What these research outcomes offer are methods of instruction, such as task analysis and systematic prompting, that may be generalizable to a broader array of skills. In fact, some newer studies described in the following sections have demonstrated these applications for more complex academic skills. Additionally, newer strategies and frameworks such as UDL have emerged, which offer new promising practices.

Before reviewing these instructional strategies, it is important to consider the concept of grade-appropriate instruction, that is, instruction that aligns with grade-level standards. Browder, Wakeman et al. (2007) described the concept of alternate achievement of skills that link to gradelevel content. One of the key criteria for alignment is to derive target skills from the grade level standards and learning activities. Grade level standards, activities, and materials should be based on age rather than current academic 
ability. The grade level standard is extended for learning For example, a student with early literacy skills who is of middle-school age would work on answering comprehension questions using text adaptations of age-appropriate novels rather than using early childhood picture books. A second important criterion is that the extensions of the standards match the grade-level content as closely as possible. If the state standard is to make inferences from graphed data, the student with severe disabilities would work with graphs to make a basic inference (e.g., which one had more). This can be called grade-appropriate academics because students learn to apply existing skills to the content in their grade level. Grade-appropriate instruction is in contrast to developmental academics in which students with severe disabilities continue to learn early childhood skills across the grade spans.

The purpose of this article is to review effective instructional strategies for promoting academic learning in the content areas of ELA, math, and science. First, the article will discuss effective interventions pertaining to ELA in the following areas: (a) read alouds, (b) decoding, (c) sight words, (d) comprehension, and (e) writing. Second, the authors will review research-based practices in mathematics in the following areas: (a) teaching computation, (b) teaching money management, and (c) expanding mathematics instruction. Finally, the review will discuss empirically supported studies of science instructional strategies in the areas of (a) vocabulary, (b) the process of inquiry, and (c) science concepts.

\section{ENGLISH LANGUAGE ARTS FOR STUDENTS WITH SEVERE DISABILITIES}

Kliewer and Landis (1999) noted that the development of literacy skills provides a critical foundation for success at school and in adult life for all students, including those with severe developmental disabilities. Nearly all academic learning requires comprehension of text whether in science, social studies, or even mathematics. Most jobs also require a minimal level of literacy to manage daily tasks. In contrast, literacy instruction has sometimes been underemphasized for students with severe developmental disabilities because of assumptions that students could not acquire these skills or because they were considered less important than other skills. Recent books on teaching students with severe disabilities provide guidance for making literacy a heightened priority (Browder \& Spooner, 2006; Copeland \& Keefe, 2007; Downing, 2005; Ryndak \& Alper, 2003).

Although literacy may be gaining priority status in planning for students with severe disabilities, a consensus has not yet been reached about what this instruction should include. The components of reading proposed by the NRP
(2000) include phonics, phonemic awareness, comprehension, vocabulary, and fluency. Students who learn to read build skills in each of these components. Browder, Gibbs, Ahlgrim-Delzell, Courtade, Mraz, and Flowers (in press) suggested a conceptual foundation for literacy composed of two outcomes: enhanced quality of life through shared literature (e.g., read alouds) and increased independence as a reader. Foley (1993) emphasized (a) phonological awareness, (b) automaticity of word recognition, (c) comprehension and the use of complex syntactic structures, and (d) comprehension of narrative and expository text. Erickson and Koppenhaver (1995) included (a) writing during daily calendar time, (b) directed reading with the teacher in a small-group or individual format, (c) use of computer software (e.g., Spell-a-Word), and (d) group activities (e.g., modeled writing component and group computer time). If planning is to be conducted across the grade bands, consideration also needs to be given to standards states set in writing, reading, research, and communication. While all of these models offer useful alternatives for literacy instruction, our review will define five areas for which there is strong or emerging research: (a) read alouds, (b) decoding, (c) sight words, (d) comprehension, and (e) writing.

\section{Literacy Instruction through Read Alouds}

Read alouds or shared stories involve a fluent reader (e.g., teacher, peer, parent) who reads age- or grade-appropriate literature to a nonreader. Evidence suggests shared stories are important to both early language development and overall literacy development (Ezell \& Justice, 2005). Moreover, participating in shared stories provides an interactive context that is meaningful, interesting, and motivating (Watkins \& Bunce, 1996). Acquiring skills to comprehend text that is read aloud may be especially important for students with severe developmental disabilities who may need this support across academic areas to augment emerging reading skills.

Although simply reading aloud to children has positive effects, shared stories can be optimized to promote children's literacy development (Justice \& Pullen, 2003). Two beneficial approaches to read alouds are dialogic reading (Whitehurst et al., 1988) and print referencing (Ezell \& Justice, 2000). Dialogic reading refers to the reader's use of evocative or interactive behaviors during the storybook reading. In dialogic reading, the reader (a) asks open-ended questions; (b) follows the child's answers with additional questions; (c) repeats and expands on what the child says; (d) gives praise, encouragement, and feedback for participation; and (e) follows the child's interest (Whitehurst et al., 1988). Similarly, print referencing refers to the reader (a) asking about the print, (b) making comments about the print, (c) posing questions about the print, (d) pointing to print 
when talking about the story, and (e) tracking the print when reading (Justice \& Pullen, 2003). Research with young children without severe developmental disabilities shows benefits in the areas of dialogic reading and print referencing to the child's oral language skills, print awareness, concepts of word, and alphabetic knowledge (Ezell \& Justice, 2000).

Shared stories have also been used successfully with students with severe developmental disabilities. Blyden (1988) found that shared book readings with adaptations (e.g., large print, pictures, sign language) increased attention skills, receptive and expressive language skills, social interaction, and active participation for the students with multiple disabilities. Browder, Mims, Spooner, Ahlgrim-Delzell, and Lee (2008) used grade-level read alouds in an elementary classroom with three students with severe intellectual and physical disabilities. The planning team used components of UDL to develop ways to adapt the read alouds. All three students gained foundational literacy skills such as choosing a book, focusing on objects related to the story, or using a voice output device to complete a repeated storyline.

Shared stories have also been successful for students with severe intellectual disabilities who also have visual impairments. Mims, Browder, Baker, Lee, and Spooner (2009) found that using least to most prompts strategy increased the number of comprehension questions (e.g., What did Alexander get stuck in his hair?) answered correctly during the story. Students responded to these questions by selecting an object that related to the main idea of the text on each page. For example, in the book Alexander and the Terrible, Horrible, No Good, Very Bad Day, Alex gets gum stuck in his hair, so the object was a pack of gum.

Similarly, Browder, Trela, and Jimenez (2007), trained teachers to use story-based lessons, one type of read alouds, with adapted grade-appropriate books to middle school students with moderate to severe disabilities. Grade-appropriate books included titles such as Cheaper by the Dozen, The Cay, and Call of the Wild. All books were adapted in the same manner (e.g., retelling the story using controlled text, providing text with picture and symbol support, text support such as adding a brief explanation of unfamiliar terms, the addition of a repeated storyline). Students in this study acquired literacy skills such as locating the title, pointing to text to follow the reader, and using pictures to answer comprehension questions. The benefits of conducting shared stories with older students may include developing lifelong leisure skills, enhanced communication skills, and acquiring tools for gaining meaning from text that may generalize to other general education content areas (Browder, Trela, \& Jiminez, 2007).

\section{Moving Beyond Shared Stories to Independent Reading}

Although all students with severe developmental disabilities may benefit from read alouds, many may also benefit from instruction that leads to greater independence as a reader. As the NRP's (2000) research summary indicated, student acquisition of phonemic awareness and phonics will be key to attaining this independence. Phonemic awareness is the understanding that words are made up of sounds as well as the ability to identify and manipulate individual sounds in words (Carnine, Silbert, Kame' ennui, \& Tarver, 2004). Researchers have found that phonemic awareness and letter knowledge are the best school-entry predictors of how well children will learn to read in the first 2 years of instruction (Ehri, 2004; Share, Jorm, MacLean, \& Matthews, 1984). Phonics instruction for students with mild disabilities is well researched; however, a review of research on reading instruction for individuals with significant cognitive disabilities (i.e., students with moderate and severe disabilities) by Browder et al. (2006) found that only a few studies focused on phonics or phonemic awareness. Although limited in number, these studies demonstrated positive benefits of phonemic awareness training and phonics instruction, but their focus was on students with moderate disabilities (Barudin \& Hourcade, 1990; Lane \& Critchfield, 1998).

Emerging evidence suggests students with a range of disabilities can acquire early phonemic awareness and phonics skills. For example, a program that has been successful for students with severe disabilities is the Early Literacy Skills Builder (ELSB; Browder, Ahlgrim-Delzell, Courtade, Gibbs, \& Flowers, 2008; Browder, Gibbs, Ahlgrim-Delzell, Courtade, \& Lee, 2007). The ELSB is based on principles of direct and systematic instruction. Students demonstrate phonemic awareness skills by clapping out syllables in words, tapping out phonemes in consonant-vowel-consonant words, identifying the first and last sound in words, finding pictures that begin or end with specific letters, pointing to letters in words that have been segmented, and pointing to pictures that represent segmented words. Direct Instruction programs like Reading Mastery (Engleman \& Bruner, 2003), and Corrective Reading (Engelmann, Hanner, \& Johnson, 1999) have also been effective with students with developmental disabilities. These curricula build on early skills acquired from programs like the ELSB.

\section{Sight Word Instruction}

To become fluent readers, students will need to build sight word vocabulary in addition to learning decoding strategies. Strategies for teaching sight words to students with severe disabilities have been well researched (Browder et al., 2006). Most of these studies reflect the priority of acquiring life skills rather than learning to read passages. For example, students have learned to read sight words to follow a job sequence (Browder \& Minavoric, 2000), to read instruction booklets (Gast, Doyle, Wolery, Ault, \& 
Farmer, 1991), or to shop for groceries (Kyhl, Alper, \& Sinclair, 1999).

One of the instructional strategies used for this sight word acquisition is time delay. Time delay involves inserting small increments of time between the delivery of a target stimulus and the delivery of a prompt across trials, resulting in the student's ability to anticipate the correct response. When using time delay, the first trial has a $0 \mathrm{~s}$ delay: The target stimulus (e.g., a flashcard with a sight word) and prompt (e.g., the teacher touches the flashcard) occur at the same time. In subsequent trails, if using progressive time delay, a gradually increasing delay is inserted between showing the sight word and modeling the answer. If using a constant time delay, the delay before delivery of the prompt remains at a constant interval. This process continues until the student anticipates the correct response. Browder, Ahlgrim-Delzell, Spooner, Mims, and Baker (2009) found that time delay has strong research evidence for teaching literacy skills like sight words to students with severe developmental disabilities.

\section{Comprehension}

The ultimate goal of reading instruction is that students will comprehend what they have read. This is thought of as the shift from' "learning to read" to "reading to learn" (Gajria, Jitendra, Sood, \& Sacks, 2009). Strategies for teaching comprehension to students with severe disabilities are not as well researched as other aspects of literacy (Perfetti, 1985; Snow, Burns, \& Griffin, 1998). For students with severe disabilities, literacy instruction has often focused on identifying sight words without a measure of comprehension (Browder. et al., 2006). When students demonstrate comprehension, it is often by matching a word to a picture (Eikeseth \& Jahr, 2001; Mechling, Gast, \& Langone, 2002) or demonstrating an activity that the word depicts (Browder \& Minarovic, 2000; Mechling \& Gast, 2003). In read alouds, students may demonstrate comprehension by using objects to answer questions (Mims et al., 2009) or by pointing to pictures (Browder, Trela, \& Jimenez, 2007). Students may learn to find the correct answer through systematic prompting with feedback (Chiang \& Lin, 2007), such as a system of least intrusive prompts used by Mims et al. (2009). Prompting in this study consisted of a verbal prompt (e.g., "let's reread") followed by re-asking the question, a model prompt (e.g., teacher touches correct response while saying, "here is the answer") followed by re-asking the question, and, finally, a physical prompt (teacher guides student to correct response).

Methods for teaching comprehension of passages are not yet evident in the research for students with severe disabilities and must be inferred from literature with other populations.
For example, the NRP recommended (a) comprehension monitoring, (b) cooperative learning, (c) graphic organizers, (d) story structure, (e) questioning, (f) question answering, (g) question generation, and (h) summarizing (National Institute of Child Health and Human Development, 2000).

\section{Writing}

Providing instruction to students with severe disabilities in the area of writing is a recent focus within literacy instruction. For writing to be fully accessible to this population, traditional views of writing may need to be expanded to include the use of assistive technology, stamps, or pictures to develop a permanent product. A review of practices on teaching writing to students with severe disabilities by Katims (2000) revealed that most writing instruction has been functional in nature: Students learned to write for a specific purpose such as making lists, addressing envelopes, or writing checks. Students also need the opportunity to learn expressive writing.

For example, Trela (2008) evaluated the effects of the I Write NOW strategy on writing opinion paragraphs with students with severe disabilities. The I Write NOW strategy consists of the following steps: (a) I think that... (b) Why do I think that? (c) Tell Reasons: If; Then; Explain, (d) Did you Name your topic? (e) Did you Order your steps? and (f) Did you Wrap it up \& restate the topic? Rather than generating written statements independently, composition was scaffolded by providing students with sentence and transition word choices. As a result of this instruction, students were able to compose opinion based paragraphs that progressed in a logical order. Similarly, students may learn to summarize main ideas, engage in creative writing, or communicate for social purposes using supports for writing such as text phrases, pictures, and speech-to-text software.

\section{Augmentative and Alternative Communication}

The use of augmentative and alternative communication (AAC) systems allows enhanced communication, especially in literacy (Beukelman \& Mirenda, 2007). AAC systems include manual signs, communication boards, voice output communication aids, and computers (Schlosser et al., 2000). AAC systems can be applied across all the strands of literacy. For example, during read alouds, students who are nonverbal may use voice output devices to answer comprehension questions, complete a repeated storyline, or make a prediction. Additionally, when providing phonics instruction, a student may demonstrate segmentation or blending using a prerecorded voice output device. In writing, students may use assistive technology to label pictures (e.g., "This is ...") or offer an opinion (e.g., "I like ..."; Cali \& Sturm, 2003). Finally, to address the research strand of literacy, students might select an appropriate topic to be researched in 
order to expand their knowledge of the topic by listening to a short nonfiction piece.

\section{Discussion of Instructional Strategies to Promote ELA}

Students with severe disabilities have historically been provided with limited opportunities for gaining literacy skills (Koppenhaver, Hendrix, \& Williams, 2007). As noted earlier, a sufficient research foundation does not yet exist for teaching language arts to students with severe disabilities. In contrast, instructional strategies such as time delay (Browder et al., 2009) or task analysis (Browder, Trela, \& Jimenez, 2007) can be applied to a wide range of language arts learning. For example, literacy skills such as the steps to read a book aloud, search the internet, or write an opinion can be task analyzed. Vocabulary, sight words, picture concepts, and letter names can be learned through time delay. Besides applying effective strategies to a wider range of literacy skills, educators can use curricula that target a comprehensive approach to early reading.

\section{MATHEMATICS FOR STUDENTS WITH SEVERE DISABILITIES}

Mathematics is another important core area for academic learning. The NCTM (2000) has identified five important components for mathematics including (1) numbers/operations, (2) algebra, (3) data analysis, (4) geometry, and (5) measurement. The NCTM (2000) also emphasizes the importance of teaching mathematical processes such as communication, reasoning, and problem solving. When these curricular recommendations are compared with how mathematics has been taught to students with severe disabilities, the narrow focus of past curricular opportunities is apparent. Browder, Spooner, et al. (2008) conducted a metaanalysis of the research on mathematics instruction for students with severe disabilities and organized the literature using the five national components of mathematics. Nearly all of the 68 studies identified focused on numbers/operations and measurement (mostly money), but some evidence was found for learning across all components.

Although restricting mathematics instruction to numbers/operation and money management is too narrow, some prioritization within the content is needed. One option is to focus on teaching students the process of solving problems so that they can apply whatever numeracy skills they have mastered. Technology such as calculators, counting jigs, graphic organizers, and manipulatives may be used to augment current numeracy skills while addressing problems that are aligned with grade-level content. For example, in the curriculum, Teaching to Standards Math (Trela, Jimenez, \& Browder, 2008), students review a problem using a read aloud. After reading a story about choosing a DVD for a group of friends to watch, the student identifies the problem statement (which DVD gets the most votes) and then uses a graphic organizer to find the solution (e.g., bar graph with picture for each person's vote).

\section{Instructional Strategies in Mathematics}

Because most of the past research on math instruction has neither been grade aligned nor problem focused, educators will need to apply effective strategies in new ways. From the meta-analysis, Browder, Spooner, et al. (2008) found using systematic prompting with feedback, task analysis, and generalization to real life contexts to be evidence-based practices in mathematics. The objective in mathematics may focus on either discrete skills or a chained task. Discrete skills consist of a single step with a definite beginning and ending that can be counted as correct or incorrect; chained skills are series of discrete steps that are linked together sequentially to form a targeted skill (Snell \& Brown, 2006). For example, a set of discrete math skills might be stating math facts during a flash card drill. The steps needed to solve a double-digit subtraction problem would be an example of a chained skill. Chained skills often involve a task analysis that depicts the specific steps and the order of performance to complete the chain. Task analyses are important for chained skills to secure instructional consistency.

The three different approaches to teaching chained skills are (1) total task presentation, (2) backward chaining, or (3) forward chaining (Cooper, Heron, \& Heward, 2007). Each may have merit in teaching a task analysis in math. In a total task presentation, the teacher may take the student through the step-by-step process of finding the area of a triangle. Or, the teacher may use backward chaining, demonstrating each step of setting up the equation and then having the student find the answer (i.e., the last step of the task analysis). Over time, the teacher instructs the student to complete the next to last step and continues to add steps until the student can do the task independently. In forward chaining, the teacher instructs the student to master the steps in a forward sequence. For example, when completing the steps of a task analysis for graphing votes, the student finds where the data point goes. The teacher or another student would complete the additional steps of the task analysis.

Whether using a task analysis with chaining or a discrete set of skills, the teacher also will want to plan systematic prompting and feedback. Stimulus prompts are modifications to the materials, and response prompts are actions performed by the instructor (Collins, 2006). A stimulus prompt might be using dots or beans glued on numerals to indicate the number represented (e.g., five dots on 5). A response prompt might be modeling the response (e.g., how to count to five). Regardless of the type of prompt incorporated with 
instruction, it is essential to utilize systematic prompt fading strategies to ensure independent skill acquisition. This might involve the application of less assistance as the student begins to make the response (e.g., a system of least prompts) or waiting longer before providing the prompt to give the student time to anticipate the response (e.g., time delay).

Teaching the student to generalize the response will involve having the student demonstrate the response with new materials, activities, people, or settings. Demonstrating the skill across materials and activities can be especially important to ensure that the mathematical concept is understood. For example, a student may memorize the task analyzed steps of completing a graph, thus accurately performing the skill, but without necessarily understanding the concept. To demonstrate mastery of content, students should use a variety of materials and activities.

\section{Teaching Computation}

The development of number sense and the ability to manipulate numbers with operations is the foundation of mathematics (NCTM, 2000). Computation is often called the gateway to higher level skills in mathematics (Butler, Miller, Lee, \& Pierce, 2001). For students with severe disabilities, computation in mathematics can be compared to independent reading in literacy. It is important for all students to have the opportunity to learn these core numeracy skills, but it is also important for students to use supports to compensate for inadequate computation skills while learning grade-appropriate content. Young students may spend considerable time learning core skills such as oneto-one correspondence, counting, addition, subtraction, and so on. Older students who lack these skills may need a number line, calculator, or manipulatives to perform the addition needed while solving an equation or computing perimeter.

In reviews of the literature on mathematics, Butler et al. (2001) and Browder, Spooner, et al. (2008) found studies demonstrating that students with severe disabilities can learn computation. These students have learned computation skills through, repeated opportunities for practice using explicit instruction, systematic prompting, and feedback. In a recent example, Cihak and Foust (2008) compared the use of number lines and touch points for teaching single-digit addition facts to three students with autism. The instructor used a system of least intrusive prompts to teach the students to add using each approach. Both strategies were effective in promoting addition skills; however, the use of touch points proved to be more efficient.

\section{Teaching Money Management}

Research on teaching measurement, specifically money skills, is an area that has received considerable emphasis in mathematics research for students with severe disabilities (Browder, Spooner, et al., 2008). Often these money management skills are taught in the context of real life activities such as naming and counting coins. These skills, however, have minimal use for older students with disabilities. In community contexts, students and adults will more likely need to know the skill of counting dollars or will use a debit card for transactions.

Researchers have used technology or community-based instruction to help students generalize skills to real life settings. Ayres, Langone, Boon, and Norman (2006) used a computer to help students learn to identify the next dollar for purchasing. In a "next dollar" strategy, students count out the dollars in the price and one more to cover the cents (e.g., $\$ 8.95$ would be eight dollars and one more). In Ayres et al. (2006), four students learned to use the next dollar strategy with use of a computer program. The computer program included simultaneous prompting to deliver instruction with massed trials in the special education classroom.

Cihak, Alberto, Taber-Doughty, and Gama (2006) compared the use of static pictures and video to teach banking and purchasing skills to six students with moderate and severe intellectual disabilities in both the special education classroom and in the community. When implementing both strategies, the special education teacher used total task chaining with a most-to-least instrusive prompting hierrachy in a group setting with the students. Results indicated the two methods were equally effective in promoting and maintaining skills needed to purchase two items from a grocery store and to withdraw $\$ 20$ from an ATM. DiPipi-Hoy and Jitendra (2004) taught parents of young adults with intellectual disabilities to deliver instruction of purchasing skills to their children with total task presentation and constant time delay for prompting. In this study, instruction took place in community settings. Results of this study indicate that parents were successful in their application of the time delay procedure, and students gained and maintained purchasing skills.

\section{Expanding Mathematics Instruction}

While most research has emphasized numbers/operations and money management, evidence shows that students with severe disabilities can learn other math skills. Neef, Nelles, Iwata, and Page (2003), used systematic instruction with massed trials and simultaneous prompting to teach a 19-year-old student with a moderate intellectual disability to solve story problems in the special education classroom. The story problems required either addition or subtraction to achieve the correct answer. This study is an important example of how students can learn problem solving. As mentioned earlier, one alternative is to teach 
all skills in mathematics using a story approach. The students would begin by reading a problem about a familiar activity (e.g., going to a ball game, ordering pizza) and then solve the problem using the current operation of focus.

More advanced skills can also be taught using task analysis and systematic prompting. For example, Jimenez et al. (2008) taught high school students with moderate developmental disabilities to use a nine-step algebra task analysis to complete a functional task. Students were able to successfully complete the math equation and solve for $\mathrm{x}$. Similarly, task analyses could be used to teach plotting $\mathrm{x}, \mathrm{y}$ coordinates, finding perimeter, comparing information in a table or graph, or other upper level mathematics activities.

Students may also need systematic instruction to acquire the terms needed to express mathematics concepts. Collins, Evans, Creech-Galloway, Karl, and Miller (2007) compared the acquisition of core content and functional words in the following formats: massed trial instruction, distributed instruction, and embedded instruction for students with severe disabilities in the general education classroom. Two students with severe disabilities learned key sight words for mathematical concepts in both the special and general education classroom. The special education teacher, general education teacher, and a paraprofessionals delivered instruction with implementation of massed trials, distributed trials, and embedded instruction following simultaneous prompting. Negligible differences in the acquisition and maintenance of skills were found across formats.

\section{Discussion of Mathematics Instruction}

Although the scope of the research on teaching math to students with severe disabilities is limited to a few strands of content, the quality of this research is high overall (Browder, Spooner, et al., 2008). Procedures such as task analyzing a mathematics operation and teaching the skills using systematic prompting and feedback are effective approaches. Nearly all math operations can be task analyzed once they are well understood. Consultation with the general education math teacher can assist in aligning instruction to core math concepts. What a special educator would call the task analysis, the math teacher would refer to as showing the steps of the process. Students with severe disabilities need many opportunities to apply the process with modeling of correct responses, manipulatives to make the process concrete, and feedback. A context for mathematics can be established through using a literacy approach, reading aloud stories of math problems that interest the student. The context also can be set by using technology that simulates real life settings (e.g., video) or through community-based instruction.

\section{SCIENCE FOR STUDENTS WITH SEVERE DISABILITIES}

To give students an opportunity to be involved in the excitement about the natural world, students of all ages and abilities should have access to all domains in science (National Academy of Sciences [NAS], 1996). Their National Science Education Standards (NSES; NAS, 1996) defined eight content standards for the instruction of science including (1) unifying concepts and processes in science, (2) science as inquiry, (3) physical science, (4) life science, (5) earth and space science, (6) science and technology, (7) science in personal and social perspectives, and (8) the history and nature of science. While research on language arts and mathematics is limited for students with severe disabilities, research in the area of science is especially sparse. Courtade et al. (2007) found a limited number of studies in which science content was taught to students with severe disabilities. For example, a search of the literature using key terms from the NSES (NAS, 1996) revealed 11 studies in which some science content (e.g., weather words, first aid skills) was taught to this population. The lack of emphasis on teaching science in the past does not mean that science is not important for students with severe disabilities, however. On the contrary, all students, including students with severe disabilities, need the opportunity to learn about the natural world in which they live to promote personal enjoyment, safety, and future career opportunities.

Standards in science are designed to integrate learning of science content, learning how to do science, and learning about science (National Research Council [NRC], 2007). A comprehensive education in science consists of three scientific abilities and understandings: (1) knowledge of the principles and concepts of science, (2) understanding of the reasoning and procedural skills, and (3) ability to create and implement investigations testing ideas using the process of inquiry (NRC, 2007). The NSES recommended the use of inquiry-based instruction for all students to learn about science in the way it actually works (NRC, 2007). A planning heuristic developed by Magnusson and Palincsar (1995), defined phases of inquiry to include having students engage with materials, investigate and describe relationships, construct explanations, and report findings.

Scientific skills and understandings will lead to the overall goal of discovery and understanding. Science content and procedural knowledge should be viewed as a cyclic process in which inquiry can guide conceptual development, and, in turn, increased conceptual knowledge can advance inquiry (Metz, 2008). Throughout the cycle of concept development and scientific inquiry, students learn to ask scientific questions and seek explanations to these questions (NRC, 2007). Unfortunately, the small research base on teaching science 
to students with severe disabilities has only a few examples of using an inquiry base or even teaching concepts. Instead, most of the research has been either completing a daily living skill (e.g., first aid) or recognizing vocabulary (e.g., weather words; Courtade et al., 2007). As in math and language arts, in science, educators will need to apply procedures proven effective in other content to new grade-appropriate objectives.

\section{Teaching Science Vocabulary}

It is well known that one barrier to learning science content is the extensive amount of vocabulary typically taught in science classes (e.g., Mastropieri \& Scruggs, 1992; Scruggs, Mastropieri, \& Okolo, 2008). Sometimes, mastering science is like learning a foreign language, because of the large amount of vocabulary necessary to develop an understanding of science concepts (e.g., Yager, 1983). Any approach to science requires learning new and sometimes domain-specific vocabulary (Scruggs et al., 2008).

Recently, researchers have demonstrated that strategies, like time delay, that have been effective for teaching sight words in literacy can be applied to academic content like science. McDonnell et al. (2006) compared embedded instruction in a general education context to small group instruction in a special education class with middle school students with moderate disabilities in various content areas. In both contexts, teachers used constant time delay, differential reinforcement, and error correction to teach students definitions of vocabulary words from the general education curriculum. One student learned abstract science vocabulary terms such as atom, element, compound, molecule, and density. Results of this study indicated that a constant time delay procedure was equally effective in both instructional arrangements in advancing the acquisition and generalization of the vocabulary definitions.

Similarly, Jameson et al. (2007) compared one-to-one embedded instruction in general education classes to one-toone massed practice instruction in a special education classroom. In each setting, special education teachers and paraprofessionals taught vocabulary definitions from the general curriculum using constant time delay, differential reinforcement, and error correction. One student learned the definitions for science terms related to states of matter (e.g., solid, liquid, gas). In contrast to the previous study, results of this study were mixed: Two the four students with moderate developmental disabilities acquired the skills more quickly in the one-to-one massed trial format than in the special education context, while another student gained skills more quickly in the embedded trial format in the general education context. The authors suggest that although embedded instruction may be a promising strategy for use in the general education setting, the massed trial format may be more effective for some discrete discrimination tasks (e.g., highly similar stimuli).

In a review on using time delay to teach literacy skills, Browder et al. (2009) clarified the requirements for the time delay procedure and emphasized the need for a comprehension measure. These requirements can be applied to any content area. First, to be time delay, the procedure must begin with trials in which the target word is paired with an immediate (no delay) prompt. For example, in a receptive teaching format, the teacher may display four words and point to the target word (e.g., molecule) while saying "Find 'molecule." Or in an expressive format, the teacher can show the word while saying, "Read 'molecule." Next, to be considered time delay, the teacher follows some specified number of no delay trials followed by sets of delayed prompt trials. In constant time delay, a small constant increment of time is used (e.g., 4 seconds) before the teacher points to the answer (or models reading it aloud). In progressive time delay, increasing increments of time are inserted across trials (e.g., 2 seconds, then 4 seconds, then 6 seconds). Students receive praise for making correct responses. Over time, this praise may be faded to come only after correct, unprompted responses. Typically, a time delay procedure produces nearly errorless learning. If errors occur, some correction procedure is used (e.g., showing the correct response) and the no delay trials may be repeated. Besides using time delay correctly, teachers also need to include a measure of comprehension. Being able to find "molecule" or "atom" may have little meaning or application. The student needs to be able to make a second response to show comprehension. For example, students might match the word to a diagram, use it to complete a sentence, or match the word to a definition.

\section{Teaching the Process of Inquiry}

The experience of inquiry is fundamental to understanding the content standards in science. According to the NAS (1996), teaching science through inquiry allows students to pose a question and then seek possible explanations that respond to the question. Inquiry can take advantage of students' natural curiosity, as they continually make observations and attempt to figure out the world around them. Teaching through inquiry prepares students to problemsolve, communicate, and develop critical thinking skills they will need throughout their lives (NRC, 2007).

Inquiry is both a goal of learning for students and a method for teaching science. For example, students should develop skills in the inquiry process, including posing a scientific question and investigating the question empirically. In addition, when students are taught using an inquiry model, scientific concepts can be developed during handson investigations or experiments. In doing so, students with 
severe disabilities learn valuable communication skills in posing questions, social skills by sharing with peers during the inquiry learning process, and life skills of observation and manipulation of materials.

Courtade, Browder, Spooner, and DiBiase (2008) trained teachers of students with moderate and severe disabilities to use a guided inquiry-based method to teach science terms and steps of the inquiry method. Teachers were trained to follow a task analysis to deliver the standardsbased content using the guided inquiry approach. Structured in an identical format for each lesson, the guided inquiry method included having the students (a) engage with the materials (e.g., asking students to state the materials to be used in the experiment, asking students to state what they know about the materials and what they would like to find out), (b) investigate and describe relationships (e.g., asking students how they will find out information about the subject, compare patterns), (c) construct an explanation (e.g., guiding students towards a scientific explanation and testing explanations through investigations), and (d) report findings (e.g., giving students an opportunity to report findings, asking students literal questions to reinforce the concept). Findings of this study indicate teachers delivered grade-appropriate science instruction across content areas in science (e.g., physical, life) to students with severe disabilities using a systematic, guided inquiry approach. Further, students increased their use of inquiry skills, and some students acquired new science vocabulary during inquiry-based instruction.

Although not described as inquiry per se, the Self-Determined Learning Model of Instruction (SDLMI) promotes some of the processes that are imperative to an inquirybased method. For example, SDLMI teaches students a "self-regulated problem-solving process to allow them to set goals, plan courses of action, self-evaluate their performance, and adjust their goals or plans accordingly" (Agran, Blanchard, \& Wehmeyer, 2000, p. 235). In this model, students answered the following questions: What is my goal? What is my plan? and What have I learned? Agran, Cavin, Wehmeyer, and Palmer (2006) examined the effects of SDLMI on the academic performance of students with moderate and severe disabilities in middle school general education classes, including science. One student, Mary, wanted to practice scientific inquiry by increasing her participation in lab activities. The instructor taught Mary to use a card listing eight activities that occurred each day during science lab (e.g., get materials, answer questions in a record book), circle the activities in which she would participate (e.g., manipulate aspects of the lab activity), and then evaluate which activities she had completed. These recent studies illustrate how a systematic approach to science inquiry, either through teaching a task analysis of an inquiry process or training students to self-monitor using the SDLMI, can increase student participation and learning in science.

\section{Teaching Science Concepts}

To truly understand and apply science, students need to learn the fundamental concepts of science in addition to science vocabulary and facts (Grossen, Carnine, Romance, \& Vitale, 2007). While learning complex knowledge forms, such as abstract scientific concepts, may be especially challenging for students with severe disabilities, students need more than fact-based learning (i.e., vocabulary words relative to the lesson) in order to include more difficult procedural and conceptual learning aligned with the general education curriculum (Lynch et al., 2007). The inquiry process, along with exposure to grade appropriate science content, helps to shape conceptual learning. Students will likely also need explicit, direct instruction on the concepts.

Conceptual learning requires students to understand the key features of objects, events, or ideas. Additionally, students must understand that concepts are categories that share characteristics with one another in order to define them as a class (Kame'enui \& Simmons, 1990; Scruggs et al., 2008). In contrast, facts have only one correct answer or example (Kame'enui \& Simmons, 1990; McCleery \& Tindal, 1999). Understanding that one object or event is different from another object or event because it belongs to a different class is a critical feature of science problem solving (e.g., controlling variables).

Unfortunately, the research on science for students with severe disabilities has primarily focused on the simpler knowledge forms such as simple facts (Courtade et al., 2007). Some recent studies provide guidance for how more complex knowledge forms can be promoted. First, in a study conducted by Jameson, McDonnell, Polychronis, and Riesen (2008), typical peers were trained to use the constant time delay procedure using embedded instruction in a general education setting with students with moderate disabilities. One student was taught to "describe the effects of smoking tobacco on specified body parts/organs" (p. 349). Peers were instructed to use a constant time delay procedure to present a stimulus set (e.g., flashcards with words such as lungs, teeth, arms, legs) to the students with moderate disabilities. The students with disabilities were required to give a correct response to the stimulus sets (e.g., when presented with a flashcard that says "lungs," the student responds with, "Gets less air. Can get cancer."). Results indicate that the peer-delivered constant time delay procedure in an embedded instructional format was effective for all students in the acquisition of the science vocabulary. This intervention is important to planning concept instruction, because students went beyond simply recognizing the word or a picture of the word to being able to 
describe some conceptual understanding. A demonstration of conceptual learning would be strengthened by having students apply this knowledge to a variety of stimuli (e.g., different organs affected by smoking).

In a study using a different approach to concept learning, Jimenez et al. (2008) used multiple exemplar training, time delay, and a self-directed learning prompt (KWHL chart) to teach students with moderate and severe intellectual disabilities to complete an inquiry lesson independently. Three middle school students used a self-directed task analysis to complete inquiry lessons in chemistry and physical science. Each concept (e.g., solutes dissolve faster in hot liquids) was used for three lessons; two with materials that were "trained" (e.g., bouillon cube and water) and one with an untrained example (e.g., salt cube and colored water). Not only were students able to self-direct using a KWHL chart through the inquiry process, they were also able to generalize the learned science concept to untrained materials and to untrained settings.

Knight, Spooner, Browder, and Wood (2009) evaluated the effects of a graphic organizer package to teach three students with moderate disabilities and autism spectrum disorders the concepts related to convection (Knight et al., 2009). The intervention included constant time delay to teach the words and definitions; examples and nonexamples to teach the concepts; model, guided practice, and independent practice to use the graphic organizer; and multiple examples of the graphic organizer to teach science concepts (e.g., precipitation, condensation, evaporation, convection). The students were given many examples of the graphic organizer so that they did not memorize the correct placement on the organizer; rather, students had to know that precipitation meant "when clouds get heavy and water falls to the ground." In this example, students learned to place the word "precipitation" on the graphic organizer when they saw the critical attributes for the concept of "precipitation" (e.g., clouds with rain, snow, hail, or sleet). Students generalized all concepts to untrained examples of the graphic organizer.

In addition to these studies specifically for students with moderate and severe disabilities, research in the area of high-incidence disabilities may offer teachers guidance on how to teach concepts to all students. Research on teaching methods to support conceptual and procedural understanding in science instruction for students with high-incidence disabilities suggests using graphic organizers, teaching vocabulary words in context, organizing information around the big ideas in science, and personalizing the lesson for the learner (Scruggs et al., 2008).

\section{Discussion of Instructional Strategies in Science}

Emerging evidence suggests that students with severe disabilities can learn grade-aligned science content and processes. In each of the studies, systematic instructional strategies were used to promote learning of science inquiry, vocabulary, and concepts. Depending on the science target skill to be taught, researchers used procedures such as embedded instruction, time delay, task analysis, and selfdirected learning. For example, embedded instruction and time delay were used across environments to increase gradeappropriate vocabulary words, definitions, and concepts. Teachers and students can direct learning of science content and inquiry skills: Teachers can be trained to use a task analysis of a guided inquiry method, or students can use self-monitoring to learn inquiry-based skills or complex science concepts. Many students have challenges applying science inquiry, vocabulary, and concept skills to other domains of science or to the real world. To increase generalization, especially of more abstract or complex concepts, students with severe disabilities will likely need exposure to multiple examples. The extant literature on teaching science to students with severe disabilities taken in combination with decades of research on effective practices used with students with high incidence disabilities, suggests that explicit instruction (e.g., use of modeling examples and nonexamples; model, lead, test), peer mediated strategies, and graphic organizers are promising instructional practices for promoting authentic academic learning in science.

\section{SUMMARY OF ACADEMIC INSTRUCTION IN ELA, MATH, AND SCIENCE}

Educational opportunities can increase access to educational, vocational, and recreational activities for students with severe disabilities (Browder, Wakeman, et al., 2007). It is evident from the research and expert opinion discussed in this article that educational opportunities are increasing for students with severe disabilities. It also is clear that academic learning of grade-aligned content in the areas of ELA, math, and science depends on effective instructional strategies appropriate for the targeted skill. There is a critical need for teachers who have knowledge and skills of researchbased and emerging instructional practices.

Time delay has recently been identified as an evidencebased practice and can be applied across content areas (Browder et al., 2009). In ELA, math, and science, gradealigned vocabulary and definitions can be taught using time delay (e.g., Jameson et al., 2007). Additionally, many chained tasks, such as completing the steps to composing a paragraph, completing a long division problem, or participating in an inquiry lesson can be taught using a task analysis of the steps. Specifically in ELA, current research supports the use of read alouds and task analytic instruction to increase foundational literacy skills as well as comprehension (e.g., Browder, Mims, et al., 2008). In math, 
studies suggest that students can learn math skills using a story-based lesson approach (e.g., Jimenez et al., 2008). Emerging evidence supports the application of a task analysis to an inquiry-based science lesson (e.g., Courtade et al., 2008).

In addition to the use of research-based strategies such as task analysis and time delay, educators can apply contemporary frameworks and strategies, such as UDL, explicit instruction, embedded instruction, and peer-mediated instruction to the content areas. For example, educators could use embedded instruction to teach vocabulary necessary to understand geometry concepts. Moreover, educators can apply empirically-based strategies that have been effective in promoting social and functional skills to gradeappropriate academic skills. Additionally, educators must consider opportunities to embed self-determination strategies into the content. For example, students could use a selfmonitoring system to complete an algebra problem. Educators also need to consider the communication and social needs of students. The use of assistive and other technologies, such as personal data assistants (PDAs) or interactive white boards (e.g., Smartboards, Promethean boards) assist a wide range of learners, including students with severe disabilities, in learning content-based information.

Although data-based recommendations are emerging on teaching academics to students with severe disabilities, additional research is needed to guide educators. Across domains in each of the content areas, studies show that students can learn fact-based skills, such as key words from an ELA lesson, multiplication facts, or science vocabulary. Additional research is needed to promote development of more complex skills, such as researching and writing about a topic of interest, finding points on a coordinate plane, or understanding abstract science concepts such as biodiversity. Educators need guidance from the literature on planning for generalization across domains, content areas, materials, and settings. To promote generalization and maintenance, educators should consider that skills learned in the classroom can be applied to home, community, and work settings. For instance, a student could research a topic of interest (e.g., owning a pet), and the classroom could take a community-based instruction field trip (e.g., a local pet store).

For over 30 years, the ultimate goal for all students is to become as independent in the community as possible (Brown et al., 1976). In order to meet this desired outcome, educators must continue to use research-based and promising practices which promote access to and participation within grade-appropriate instructional content (IDEA, 1997, 2004). Considerations of life skills, self-determination, transition, and social skills continue to be important areas to address for this population. In planning instruction for students with severe disabilities, the current challenge is to integrate opportunities for authentic academic learning with these other considerations.

\section{REFERENCES}

Agran, M., Blanchard, C., \& Wehmeyer, M. L. (2000). Promoting transition goals and self-determination through student self-directed learning: The self-determined learning model of instruction. Education and Training in Mental Retardation and Developmental Disabilities, 35, 351-364.

Agran, M., Cavin, M., Wehmeyer, M., \& Palmer, S. (2006). Participation of students with moderate to severe disabilities in the general curriculum: The effects of the self-determined learning model of instruction. Research \& Practice for Persons with Severe Disabilities, 31, 230-241.

Ayres, K. M., Langone, J., Boon, R. T., \& Norman, A. (2006). Computer-based instruction for purchasing skills. Education and Training in Developmental Disabilities, 41, 253-263.

Barudin, S. I., \& Hourcade, J. J. (1990). Relative effectiveness of three methods of reading instruction in developing specific recall and transfer skills in learners with moderate to severe mental retardation. Education and Training in Mental Retardation and Developmental Disabilities, 21, 286-291.

Beukelman, D. R., \& Mirenda, P. (Eds). (2007). Augmentative and alternative communication: Supporting children \& adults with complex communication needs. Baltimore: Brookes.

Blyden, A. E. (1988). Shared story reading for severely handicapped learners. Reading Improvement, 25, 67-70.

Browder, D. M., Ahlgrim-Delzell, L., Courtade, G., Gibbs, S. L., \& Flowers, C. (2008). Evaluation of the effectiveness of an early literacy program for students with significant developmental disabilities. Exceptional Children, 75, 33-52.

Browder, D., Ahlgrim-Delzell, L., Spooner, F., Mims, P. J., \& Baker, J. (2009). Using time delay to teach literacy to students with severe developmental disabilities. Exceptional Children, 75, 343-364.

Browder, D., Gibbs, S., Ahlgrim-Delzell, L., Courtade, G., \& Lee, A. (2007). Early literacy skills builder. Verona, WI: Attainment.

Browder, D. M., Gibbs, S. L., Ahlgrim-Delzell, L., Courtade, G., Mraz, M., \& Flowers, C. (in press). Literacy for students with significant disabilities-What should we teach and what should we hope to achieve? Remedial and Special Education.

Browder, D. M., Mims, P. J., Spooner, F., Ahlgrim-Delzell, L., \& Lee, A. (2008). Teaching elementary students with multiple disabilities to participate in shared stories. Research and Practice for Persons with Severe Disabilities, 33, 3-12.

Browder, D. M., \& Minavoric, T. J. (2000). Utilizing sight words in self-instruction training for employees with moderate mental retardation in competitive jobs. Education and Training in Mental Retardation and Developmental Disabilities, 35, 78-89.

Browder, D. M., \& Spooner, F. (Eds). (2006). Teaching language arts, math, and science to students with significant cognitive disabilities. Baltimore: Brookes.

Browder, D. M., Spooner, F., Ahlgrim-Delzell, L., Harris, A., \& Wakeman, S. (2008). A meta-analysis on teaching mathematics to students with significant cognitive disabilities. Exceptional Children, 74, 407-432.

Browder, D. M., Trela, K., \& Jimenez, B. (2007). Training teachers to follow a task analysis to engage middle school students with moderate and severe developmental disabilities in grade-appropriate literature. Focus on Autism and Other Developmental Disabilities, 22, 206-219. 
Browder, D. M., Wakeman, S. Y., Flowers, C., Rickelman, R. J., Pugalee, D., \& Karvonen, M. (2007). Creating access to the general curriculum with links to grade-level content for students with significant cognitive disabilities. The Journal of Special Education, 41, 2-16.

Browder, D. M., Wakeman, S. Y., Spooner, F., Ahlgrim-Delzell, L., \& Algozzine, B. (2006). Research on reading instruction for individuals with significant cognitive disabilities. Exceptional Children, 72, 392-408.

Brown, L., Nietupski, J., \& Hamre-Nietupski, S. (1976). Criterion of ultimate functioning. In M. A. Thomas (Ed.), Hey, don't forget about me! Education's investment in the severely, profoundly, and multiply handicapped (pp. 2-15). Reston, VA: Council for Exceptional Children.

Butler, F. M., Miller, S. P., Lee, K., \& Pierce, T. (2001). Teaching mathematics to students with mild-to-moderate mental retardation: A review of literature. Mental Retardation, 39, 20-31.

Cali, K., \& Sturm, J. (2003). The development of narrative and nonnarrative writing genres in beginning writers. Paper presented at annual meeting of the North Carolina Association for Research in Education, Apex, NC.

Carnine, D., Silbert, J., Kame'ennui, E. J., \& Tarver, S. (2004). Direct instruction reading ( 3 rd ed.). Columbus, $\mathrm{OH}$ : Merrill.

CAST (2008). Universal design for learning guidelines version 1.0. Wakefield, MA: Author.

Chiang, H. M., \& Lin, Y. H. (2007). Reading comprehension instruction for students with autism spectrum disorder: A review of the literature. Focus on Autism and Other Developmental Disabilities, 22, 259-267.

Cihak, D. F., Alberto, P. A., Taber-Doughty, T., \& Gama, R. I. (2006). A comparison of static picture prompting and video prompting simulation strategies using group instructional procedures. Focus on Autism and Other Developmental Disabilities, 21, 89-99. doi: $10.1177 / 10883576060210020601$

Cihak, D. F., \& Foust, J. L. (2008). Comparing number lines and touch points to teach addition facts students with autism. Focus on Autism and Other Developmental Disabilities, 23, 131-138. doi: $10.1177 / 1088357608318950$

Collins, B. C. (Ed.). (2006). Moderate and severe disabilities: A foundational approach. Upper Saddle River, NJ: Prentice Hall.

Collins, B. C., Evans, A., Creech-Galloway, C., Karl, J., \& Miller, A. (2007). Comparison of the acquisition and maintenance of the teaching functional and core content sight words in special and general education settings. Focus on Autism and Other Developmental Disabilities, 22, 220-233.

Cooper, J. O., Heron, T. E., \& Heward, W. L. (2007). Applied behavior analysis (2nd ed.). Upper Saddle River, NJ: Pearson/Merrill/ Prentice-Hall.

Copeland, S. R., \& Keefe, E. B. (Eds.). (2007). Effective literacy instruction for students with moderate or severe disabilities. Baltimore: Brookes.

Courtade, G., Browder, D., Spooner, F., \& DiBiase, W. (2008). The effects of inquiry-based science instruction on teachers of students with significant disabilities. Manuscript submitted for publication.

Courtade, G., Spooner, F., \& Browder, D. M. (2007). Review of studies with students with significant cognitive disabilities which link to science standards. Research and Practice for Persons with Severe Disabilities, 32, 43-49.

DiPipi-Hoy, C., \& Jitendra, A. (2004). A parent-delivered intervention to teach purchasing skills to young adults with disabilities. The Journal of Special Education, 38, 144-157. doi: 10.1177/ 00224669040380030201
Downing, J. E. (Ed.). (2005). Teaching communication skills to students with severe disabilities (2nd ed.). Baltimore: Brookes.

Dymond, S. K., Renzaglia, A., Rosenstein, A., Chun, E. J., Banks, R. A., Niswander, V., \& Gilson, C. L. (2006). Using a participatory action research approach to create a universally designed inclusive high school course: A case study. Research \& Practice for Persons with Severe Disabilities, 31, 293-308.

Ehri, L. C. (2004). Teaching phonemic awareness and phonics: An explanation of the National Reading Panel meta-analyses. In P. McCardle \& V. Chhabra (Eds.), The voice of evidence in reading research (pp. 153-186). Baltimore, MD: Brookes.

Eikeseth, S., \& Jahr, E. (2001, July 1). The UCLA reading and writing program: An evaluation of the beginning stages. Research in Developmental Disabilities, 22, 289-307.

Engleman, S., \& Bruner, E. (2003). Reading mastery. Worthington, $\mathrm{OH}$ : SRA/McGraw-Hill.

Engelmann, S., Hanner, S., \& Johnson, G. (1999). Corrective Reading-Series Guide. Columbus, OH: SRA/McGraw Hill.

Erickson, K. A., \& Koppenhaver, D. A. (1995). Developing a literacy program for children with severe disabilities. The Reading Teacher, 48, 676-685.

Ezell, H. K., \& Justice, L. M. (2000). Increasing the print focus of shared reading interactions through observational learning. American Journal of Speech-language Pathology, 9, 36-47.

Ezell, H. K., \& Justice, L. M. (2005). Shared storybook reading: Building young children's language \& emergent literacy skills. Baltimore: Brookes.

Foley, B. E. (1993). The development of literacy in individuals with severe congenital speech and motor impairments. Top Lang Disorders, $13,16-32$.

Gajria, M., Jitendra, A. K., Sood, S., \& Sacks, G. (2007). Improving comprehension of expository text in students with $L D:$ A research synthesis. Journal of Learning Disabilities, 40, 210-225.

Gast, D. L., Doyle, P. M., Wolery, M., Ault, M. J., \& Farmer, J. A. (1991). Assessing the acquisition of incidental information by secondary-age students with mental retardation: Comparison of response. prompting strategies. American Journal of Mental Deficiency, 96, 63-80.

Grossen, B. J., Carnine, D. W., Romance, N. R., \& Vitale, M. R. (2007). Effective strategies for teaching science. In M. D. Coyne, E. J. Kame'enui, \& D.W. Carnine, (Eds.), Effecrive teaching strategies that accommodate diverse learners (pp. 171-201). Upper Saddle River, NJ: Pearson Education.

Individuals with Disabilities Education Act Amendments of 1997, PL 105-17, 20 U.S.C. $\$ 1400$ et seq.

Individuals with Disabilities Education Improvement Act of 2004, PL 108-466, 20 U.S.C. $\$ 1400$, H.R. 1350.

Jameson, J. M., McDonnell, J., Johnson, J. W., Riesen, T., \& Polychronis, S. (2007). A comparision of one to one embedded instruction in the general education classroom and one to one massed practice instruction in the special education classroom. Education and Treatment of Children, 30, 23-44.

Jameson, J. M., McDonnell, J., Polychronis, S., \& Riesen, T. (2008). Embedded, constant time delay instruction by peers without disabilities in general education classrooms. Intellectual and Devel. opmental Disabilities, 46, 346-363.

Jimenez, B. A., Browder, D. M., \& Courtade, G. (2008). Teaching an algebraic equation to high school students with moderate developmental disabilities. Education and Training in Developmental Disabilities, 43, 266-274.

Justice, L. M., \& Pullen, P. C. (2003). Promising interventions for promoting emergent literacy skills. Topics in Early Childhood Special Education, 23, 99-113. doi: 10.1177/02711214030230030101 
Kame'enui, E. J., \& Simmons, D. C. (1990). Designing instructional strategies: The prevention of academic learning problems. Columbus, OH: Merrill.

Katims, D. S. (2000). Literacy instruction for people with mental retardation: Historical highlights and contemporary analysis. Education and Training in Mental Retardation and Developmental Disabilities, 35, 3-15.

Kliewer, C., \& Landis, D. (1999). Individualizing literacy instruction for young children with moderate to severe disabilities. Exceptional Children, 66, 85-100.

Knight, V., Spooner, F., Browder, D., \& Wood, C. (2009). Teaching Science Vocabulary and Concepts Using Graphic Organizers to Students with Autism Spectrum Disorder. Manuscript in preparation.

Koppenhaver, D. A., Hendrix, M. P., \& Williams, M. A. (2007). Toward evidence-based literacy interventions for children with severe and multiple disabilities. Seminars in Speech and Language, 28, 79-89.

Kyhl, R., Alper, S., \& Sinclair, T. J. (1999). Acquisition and generalization of functional words in community grocery stores using videotaped instruction. Career Development for Exceptional Individuals, 22(1), 55-67.

Lane, S. D., \& Critchfield, T. S. (1998). Classification of vowels and consonants by individuals with moderate mental retardation: Development of arbitrary relations via match-to-sample training with compound stimuli. Journal of Applied Behavior Analysis, 31, $21-41$.

Lynch, S., Taymans, J., Watson, W. A., Ochsendorf, R. J., Pyke, C., \& Szesze, M. J. (2007). Effectiveness of a highly random science curricula for students with disabilities in general education classrooms. Exceptional Children, 73, 202-223.

Magnusson, S. J., \& Palincsar, A. S. (1995). The learning environment as a site of science education reform. Theory into Practice, 34, 43-50.

Mastropieri, M. A., \& Scruggs, T. E. (1992). Science for students with disabilities. Review of Educational Research, 62, 377-411. doi: 10.3102/00346543062004377

McCleery, J. A., \& Tindal, G. A. (1999). Teaching the scientific method to at-risk students and students ${ }^{-}$with learning disabilities through concept anchoring and explicit instruction. Remedial and Special Education, 20, 7-18.

McDonnell, J., Johnson, J., Polychronis, S., Riesen, T., Jameson, M., \& Kercher, K. (2006). Comparison of one-to-one embedded instruction in general education classes with small group 31 instruction in special education classes. Education and Training in Developmental Disabilities, 41, 125-138.

Mechling, L., \& Gast, D. (2003). Multi-media instruction to teach grocery word associations and store location: A study of generalization. Education and Training in Developmental Disabilities, 38 , 62-76.

Mechling, L., Gast, D., \& Langone, J. (2002). Computer-based video instruction to teach persons with moderate intellectual disabilities to read grocery aisle signs and locate items. Journal of Special Education, 35, 224.

Metz, K. E. (2008). Narrowing the gulf between the practices of science and the elementary school science classroom. Elementary School Journal, 109, 138-161.

Mims, P. J., Browder, D. M., Baker, J., Lee, A., \& Spooner, F. (2009). Increasing comprehension of students with significant intellectual disabilities and visual impairments during shared stories. Education and Training in Developmental Disabilities, 44, 409-420.
National Academy of Sciences (NAS). (1996). National Science Education Standards. Washington, DC: National Academy Press.

National Council of Teachers of Mathematics (NCTM). (2000). Principles and standards for school mathematics. Reston, VA: Author.

National Institute of Child Health and Human Development. (2000). Teaching children to read: An evidence-based assessment of the scientific literature on reading and its implications for reading instruction. Washington, DC: U.S. Government Printing Office.

National Reading Panel (NRP). (2000). A report of the National Reading Panel: Teaching children to read. Washington, DC: National Institute of Child Health and Human Development.

National Research Council (NRC). (2007). Taking science to school: Learning and teaching science in grades $K-8$. Washington, DC: The National Academies Press.

Neef, N. A., Nelles, D. E., Iwata, B. A., \& Page, T. J. (2003). Analysis of precurrent skills in solving mathematical story problems. Journal of Applied Behavior Analysis, 36, 21-33.

Perfetti, C. A. (1985). Reading ability. New York: Oxford Press.

Ryndak, D. L., \& Alper, S. (2003). Curriculum and instruction for students with significant disabilities in inclusive settings (2nd ed.). Boston: Allyn and Bacon.

Schlosser, R., McGhie-Richmond, D., Blackstien-Adler, S., Mirenda, P., Antonious, K., \& Janzen, P. (2000). Training a school team to integrate technology meaningfully into the curriculum: Effects on student participation. Journal of Special Education Technology, $15,31-44$.

Scruggs, T. E., Mastropieri, M. A., \& Okolo, C. M. (2008). Science and Social Studies for Students with Disabilities, Focus on Exceptional Children, 41, 1-24.

Share, D., Jorm, A., MacLean, R., \& Matthews, R. (1984). Sources of individual differences in reading achievement. Journal of Educational Psychology, 76, 1309-1324.

Snell, M. E., \& Brown, F. (Eds.). (2006). Instruction of students with severe disabilities (6th ed.). Upper Saddle River, NJ: Prentice Hall.

Snow, C., Burns, M. S., \& Griffin, P. (Eds.). (1998). Preventing reading difficulties in young children. Washington, DC: National Academy of Sciences.

Trela, K. (2008). Effects of I Write Now strategy on high school students with significant cognitive disabilities' participation in composing an opinion paragraph. Unpublished doctoral dissertation, University of North Carolina at Charlotte.

Trela, K., Jimenez, B. A., \& Browder, D. M. (2008). Teaching to the standards in mathematics: A literacy-based approach for students with moderate and severe disabilities. Verona, WI: Attainment.

Watkins, R. V., \& Bunce, B. H. (1996). National literacy: Theory and practice for preschool intervention programs. Topics in Early Childhood Special Education, 16, 191-212.

Whitehurst, G. J., Falco, F. L., Lonigan, C. J., Fischel, J. E., DeBaryshe, B. D., Valdez-Menchaca, M. C., et. al. (1988). Accelerating language development through picture book reading. Developmental Psychology, 24, 552-559.

Yager, R. E. (1983). The importance of terminology in teaching K-12 science. Journal of Research in Science Teaching, 20, 577-588. 